\title{
Estrogen Deficiency Aggravates Insulin Resistance and Induces $\beta$-Cell Loss and Diabetes in Female New Zealand Obese Mice
}

Authors

Affiliation

\section{H. Vogel ${ }^{*}$, F. Mirhashemi" , B. Liehl, F. Taugner, O. Kluth, R. Kluge, H.-G. Joost, A. Schürmann}

Departments of Pharmacology and Experimental Diabetology, German Institute of Human Nutrition, Potsdam-Rehbruecke, Germany

Key words
estrogen
ovariectomy
obesity
hyperglycemia
ß $\beta$-cell failure

received 02.11 .2012 accepted 22.11.2012

\section{Bibliography}

Dol http://dx.doi.org/

10.1055/s-0032-1331700

Published online:

January 15, 2013

Horm Metab Res 2013;

45: 430-435

(c) Georg Thieme Verlag KG

Stuttgart · New York

ISSN 0018-5043

Correspondence

\section{Dr. A. Schürmann}

Department of Experimental Diabetology

German Institute of Human Nutrition

Arthur-Scheunert-Allee

114-116

14558 Nuthetal

Germany

Tel.: + 49/33200/882368

Fax: $+49 / 33200 / 882334$

schuermann@dife.de

\section{Abstract \\ $\nabla$}

In several rodent strains such as the New Zealand Obese (NZO) mouse, the incidence of obesityassociated diabetes mellitus is much higher in males than in females. In the present study, we investigated the effects of ovariectomy on glucose homeostasis in female NZO mice in order to elucidate the mechanism of their diabetes resistance. NZO females were ovariectomized at the age of 4 weeks, received a high-fat diet and body weight, body fat, glucose and insulin tolerance were investigated in comparison to sham-operated mice. In a second experiment, operated mice were fed a carbohydrate-free diet up to the age of 19 weeks before they received the high-fat diet. In comparison with a shamoperated control group, ovariectomized female NZO mice exhibited similar body weights, a

\section{Introduction}

Obese rodents with susceptibility for hyperglycemia such as the New Zealand Obese (NZO) mouse have been studied as models for the human obesity-associated type 2 diabetes [1-4]. At the age of 10-20 weeks, the strain develops a progressive failure of insulin-secreting $\beta$-cells, and a severely decompensated glucose homeostasis with glucosuria and blood glucose levels $>20 \mathrm{mM}$. In NZO as well as in other rodent models of type 2 diabetes, for example, Zucker diabetic fatty (ZDF) rats or diabetes induced by multiple low dose streptozotocin, females are protected from hyperglycemia and $\beta$-cell death, whereas males develop overt insulin-deficient diabetes $[5,6]$. These data suggest that sex hormones have a major impact on glucose homeostasis by either modifying insulin secretion or insulin sensitivity. Beneficial effects

*Equal contribution reduced glucose tolerance, developed significantly higher blood glucose levels, lost insulin producing $\beta$-cells, which finally resulted in a diabetes prevalence of $73 \%$ at the age of 16 weeks vs. $25 \%$ in controls. Similar to male NZO mice, ovariectomized females presented a more severe insulin resistance in the insulin tolerance test than sham-operated controls. Furthermore, the more severe insulin resistance in ovariectomized mice preceded the development of diabetes and pancreatic insulin depletion that was caused by a dietary regimen of carbohydrate restriction and subsequent re-exposure. In summary our data demonstrate that estrogen protects NZO females from $\beta$-cell loss and obesity-associated diabetes mellitus. This effect is due to a reduced insulin resistance and possibly also to a reduced sensitivity of $\beta$-cells to glucolipotoxic conditions. of $17 \beta$-estradiol (E2) on insulin sensitivity have been proved by characterization of transgenic models with altered E2 secretion or E2 action such as the estrogen receptor $\alpha$ knockout (ERKO) mouse [7]. This model is characterized by insulin resistance and impaired glucose tolerance in both sexes [8]. In humans, estrogen deficiency at menopause is associated with an increased risk for the development of type 2 diabetes and can subsequently be improved by estrogen replacement $[9,10]$.

The cellular and molecular mechanisms of the antidiabetic effects of E2 are largely unknown, although several tissue-specific actions of E2 on glucose homeostasis have been described during the last years. Estrogen has been found to decrease hepatic glucose production, to stimulate fatty acid oxidation in liver, and to enhance glucose transport in skeletal muscle. Estrogen also protects pancreatic $\beta$-cell function and survival in conditions of oxidative stress (reviewed in [11]). 
In summary, the impact of estrogen on glucose metabolism has been demonstrated in a wide range of rodent models and human studies. However, direct proof that estrogen is responsible for the diabetes resistance of female obese mice is still lacking. Thus, we studied ovariectomized NZO mice in order to investigate the effects of estrogen deficiency on the development of obesity and diabetes, in particular with regard to insulin resistance and $\beta$-cell loss. Towards this goal, we used a dietary regimen that allows dissociation of the effects of obesity (lipotoxicity) and hyperglycemia (glucotoxicity) by carbohydrate restriction and re-exposure $[12,13]$.

\section{Materials and Methods}

$\nabla$

\section{Animals}

Male NZO/HIBomDife mice (R. Kluge, German Institute of Human Nutrition, Nuthetal, Germany) from our own colony that was generated from an inbred strain NZO/HILtJ (Jax Mice Database 002105) [4] were housed in groups of 5 per cage (type II macrolon) at a temperature of $21 \pm 1{ }^{\circ} \mathrm{C}$ with a 12-h light-dark cycle (lights on at 06:00 h). Animals had free access to food and water, and were kept in accordance with the National Institutes of Health guidelines for the care and use of laboratory animals. All experiments were approved by the Ethics Committee of the State Ministry of Agriculture, Nutrition and Forestry (State of Brandenburg, Germany).

\section{Diets and study design}

Experiment 1: From weaning at the age of 3 weeks onwards, mice received a high-fat diet containing (wt/wt) $28 \%$ fat, $20 \%$ protein, and $40 \%$ carbohydrates with a total metabolizable energy of $21.9 \mathrm{~kJ} / \mathrm{g}$. Fat content normalized per total energy was $51.4 \%$, protein $16.2 \%$, and carbohydrates $32.4 \%$.

Experiment 2: After weaning mice received a carbohydratefree diet purchased from Altromin (custom made by the manufacturer, Lage, Germany) containing (wt/wt) $30.2 \%$ fat and $26.4 \%$ protein with a total metabolizable energy of $16.9 \mathrm{~kJ} / \mathrm{g}$. Fat content normalized per total energy was $71.2 \%$ and protein content was $28.8 \%$. The dietary intervention was started at week 19 with the high-fat diet (carbohydrate-containing diet) used in Experiment 1 .

\section{Body weight and body composition}

Body weight was measured with an electronic scale. In addition, body fat and lean mass was measured by NMR with a Bruker Minispec instrument (Echo Medical Systems, Houston, TX, USA) as described previously [14].

\section{Analysis of blood parameters}

Blood samples were collected at the indicated days from the tail vein of fed mice between 09:00 and 11:00 AM. Blood glucose was determined with an Ascensia ELITE XL glucose meter (Bayer Health Care, Leverkusen, Germany). Plasma insulin was assayed with the Mouse Insulin Ultrasensitive ELISA kit (DRG Instruments, Marburg, Germany).

\section{Oral glucose tolerance test}

Animals were fasted for $16 \mathrm{~h}$ (overnight) before the experiment. Each animal received an oral dosage of glucose $(2 \mathrm{~g} / \mathrm{kg}$ body weight). Samples for determination of blood glucose and plasma insulin were obtained at $0,7.5,15,30,60,120$, and 240 min from the tail tip. To minimize distress, mice were kept in their accustomed cage and had free access to water.

\section{Insulin tolerance test}

Animals were fasted for $6 \mathrm{~h}$ ( $7 \mathrm{AM}-1 \mathrm{PM}$ ) before the experiment. Each animal received a single ip injection of insulin $(1 \mathrm{IU} / \mathrm{kg}$ body weight) and blood samples for the determination of blood glucose levels were obtained at $0,15,30,45,60$, and $90 \mathrm{~min}$ from the tail tip.

\section{Pancreatic insulin content}

For detection of total pancreas insulin, whole pancreas was homogenized in ice-cold acid ethanol $(0.1 \mathrm{~mol} / 1 \mathrm{HCl}$ in $70 \%$ ethanol) and incubated for $24 \mathrm{~h}$ at $4{ }^{\circ} \mathrm{C}$. After centrifugation $(16000 \mathrm{~g}$, $10 \mathrm{~min}$ ) insulin was detected in the supernatant with the Mouse Insulin Ultrasensitive ELISA kit (DRG Instruments).

\section{Surgery}

Mice at the age of 4 weeks were anesthesized with $0.05 \mathrm{mg} / \mathrm{kg}$ fentanyl, $5 \mathrm{mg} / \mathrm{kg}$ climazolam, and $0.5 \mathrm{mg} / \mathrm{kg}$ medetomidin i.p. and placed on heating plates $\left(35^{\circ} \mathrm{C}\right)$. Hair was clipped over the surgical area and scrubbed with $10 \%$ povidone iodine solution followed by $70 \%$ ethanol. A small midline incision was made in the skin halfway between the middle of the back and the base of the tail, starting at the last rib, followed by an incision on the abdominal muscle to enter the abdominal cavity. Using forceps, the periovarian fat was gently grasped to lift the ovary and the oviduct and cranial part of the uterine horn was crushed distal to the ovary. The entire ovary was removed with a single cut above the clamped area. The uterine horn was returned into the abdomen, and the process was repeated on the other side. The abdominal wall incision was sutured and the skin incision was closed using wound clips. Immediately after surgery anesthesia was antagonized with $1.2 \mathrm{mg} / \mathrm{kg}$ naloxon, $0.5 \mathrm{mg} / \mathrm{kg}$ sarmazenil, and $2.5 \mathrm{mg} / \mathrm{kg}$ atipamezol. Animals were treated preemptively and for $72 \mathrm{~h}$ (twice daily) after surgery with carprofen ( $4 \mathrm{mg} / \mathrm{kg}$ ).

\section{Immunohistochemistry of pancreatic islets}

Pancreatic tissue was excised, fixed, and stained for insulin as previously described $[12,13]$.

\section{Statistical analysis}

Values are reported as means \pm SEM, unless otherwise noted. Differences between sham and ovariectomized females were tested by 2-tailed Student's $t$-test. Statistical analysis for more than 2 groups was performed using 2-way analysis of variance and post hoc with Scheffe's test (STATVIEW Program, SAS Institute Inc., Cary, NC). A p-value smaller than $0.05(\mathrm{p}<0.05)$ was considered significant.

\section{Results}

$\nabla$

\section{Ovariectomy accelerates the development of diabetes} in NZO females

NZO females were ovariectomized or sham operated at the age of 4 weeks, and body weight ( $\bullet$ Fig. 1a, left panel), body fat (right panel), blood glucose ( $\bullet$ Fig. 1b, left panel), and diabetes prevalence (right panel) were monitored up to the age of 16 weeks under HFD feeding. Both ovariectomized NZO females and sham-operated controls developed a marked obesity with no difference in body weight or fat accumulation between the 2 

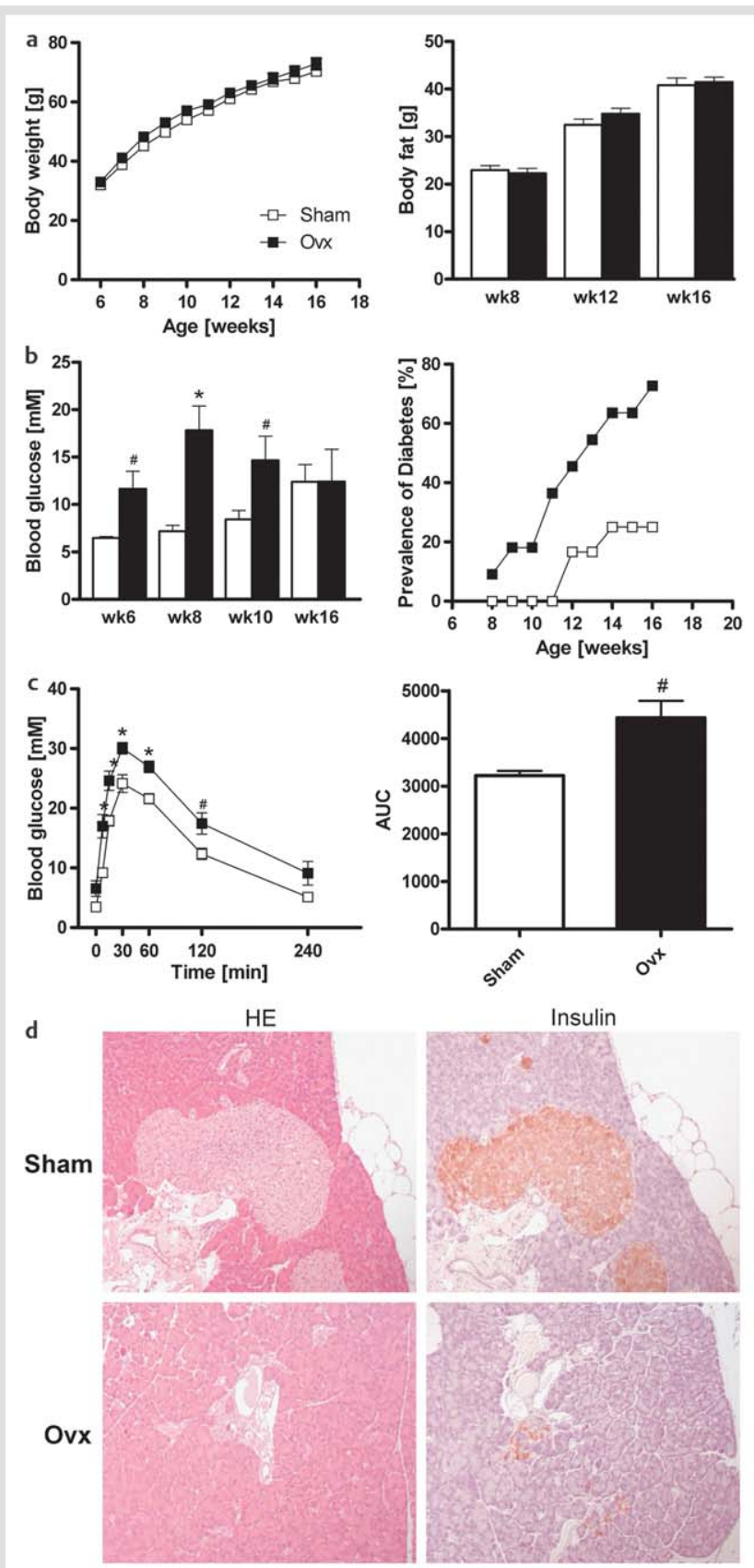

Fig. 1 Effect of ovariectomy in NZO females fed a high-fat diet. a Development of body weight (left panel) and body fat (right panel) of ovariectomized (Ovx) NZO females as compared with sham-operated controls (Sham) that were kept on a HFD. b Time course of blood glucose levels in HFD-fed mice at the indicated time points (left panel) and prevalence of diabetes (hyperglycemia $>16.6 \mathrm{mM}$ ) (right panel). c Blood glucose in NZO females fasted overnight and exposed to an oral glucose bolus (left panel), and calculation of the area under the curve (AUC) (right panel). d Immunohistochemistry of insulin in pancreatic sections of NZO mice. Data represents means \pm SEM $\left({ }^{*} p<0.005\right.$; $\left.\# p<0.05\right)$; Sham: $n=12$; Ovx: $\mathrm{n}=11$.

groups. In contrast, starting already at the age of 6 weeks, blood glucose levels were significantly higher in the ovariectomized group than in the controls ( $\bullet$ Fig. 1b, left panel), resulting in a steep increase in the prevalence of diabetes (blood glucose $>16.6 \mathrm{mM}$ ) ( $\bullet$ Fig. 1b, right panel). At the age of 16 weeks, diabetes prevalence reached $73 \%$ in the ovariectomized group as compared with $25 \%$ in the control group ( $\odot$ Fig. 1b, right panel), approaching the diabetes prevalence usually seen in male NZO [4]. Thus, ovariectomy had apparently abolished the partial diabetes resistance of NZO females. Because of the severity of their diabetes, most ovariectomized animals ( 7 out of 11 ) had to be euthanized before week 16 . Consequently, only nondiabetic animals were left at week 16, explaining the similar blood glucose levels in both groups at this time point ( $\bullet$ Fig. 1b, left panel). Oral glucose tolerance tests performed at week 10 showed an impaired glucose tolerance in females who underwent ovariectomy as compared with the sham-operated controls ( $\bullet$ Fig. 1c). The development of diabetes in male NZO is associated with a marked loss of $\beta$-cells. Thus, in order to ascertain that ovariectomy had produced a similar phenotype in NZO females, histology of pancreatic sections ( $\bullet$ Fig. 1d, left panel) including immunohistochemistry of insulin (right panel) was performed. In sham-operated controls, normal islets abundant in immunoreactive insulin were detected throughout. In contrast, ovariectomized, diabetic NZO females had very few islets. Rather, few clumps of scattered $\beta$-cells representing remnants of islets were visible. Thus, hyperglycemia in female mice lacking ovaries is associated with $\beta$-cell loss, similar to that seen in males. In conclusion, estrogen deficiency accelerates the development of diabetes in NZO females, thereby producing a diabetic phenotype similar to that seen in males.

\section{Ovariectomy aggravates insulin resistance in NZO females}

We have previously established a dietary regimen that dissociates obesity and diabetes in male NZO [13]: Mice fed a carbohydrate-free, high-fat diet develop severe obesity but no hyperglycemia and $\beta$-cell loss. Exposure to dietary carbohydrates leads to a rapid increase of plasma glucose in NZO and subsequent loss of $\beta$-cells [12].

Here we used this regimen in order to test whether ovariectomy had aggravated insulin resistance or $\beta$-cell failure. After weaning, ovariectomized and sham-operated females as well as males received a carbohydrate-free diet containing (wt/wt) $30.2 \%$ fat and $26.4 \%$ protein until the age of 19 weeks. This dietary regimen caused a continuous increase in body weight in all 3 groups resulting in massive obesity ( $\bullet$ Fig. 2a). Body weight gain was higher in estrogen-deficient females as compared with the sham-operated controls, and approached that of males at week 16-19. In contrast to the results obtained under a carbohydratecontaining diet, blood glucose levels remained below $10 \mathrm{mM}$ in all groups throughout the experiment ( $\bullet$ Fig. 2b). Under these carbohydrate-free conditions, insulin levels are lower as when mice receive a combination of high fat and carbohydrates. As shown in $\bullet$ Fig. 2c, plasma insulin levels were substantially higher in ovariectomized females and in male NZO mice, suggesting a more pronounced insulin resistance in these groups. Glucose homeostasis was further studied by insulin and glucose tolerance tests ( $\bullet$ Fig. 3). Animals were fasted for $6 \mathrm{~h}$ before they received a single ip injection of insulin and blood glucose concentrations were recorded over $90 \mathrm{~min}$. As shown in $\bullet$ Fig. 3a, ovariectomized females and male NZO exhibited a lower effect of insulin on blood glucose levels than the sham-operated controls, and the reduced insulin sensitivity of ovariectomized females appeared similar to that of male mice. The glucose tolerance test revealed an impaired response to an oral application of glucose in NZO males as well as in ovariectomized females in comparison to the sham controls ( $\bullet$ Fig. 3 b). In conclusion, the data obtained with a dietary regimen of carbohydrate restriction 

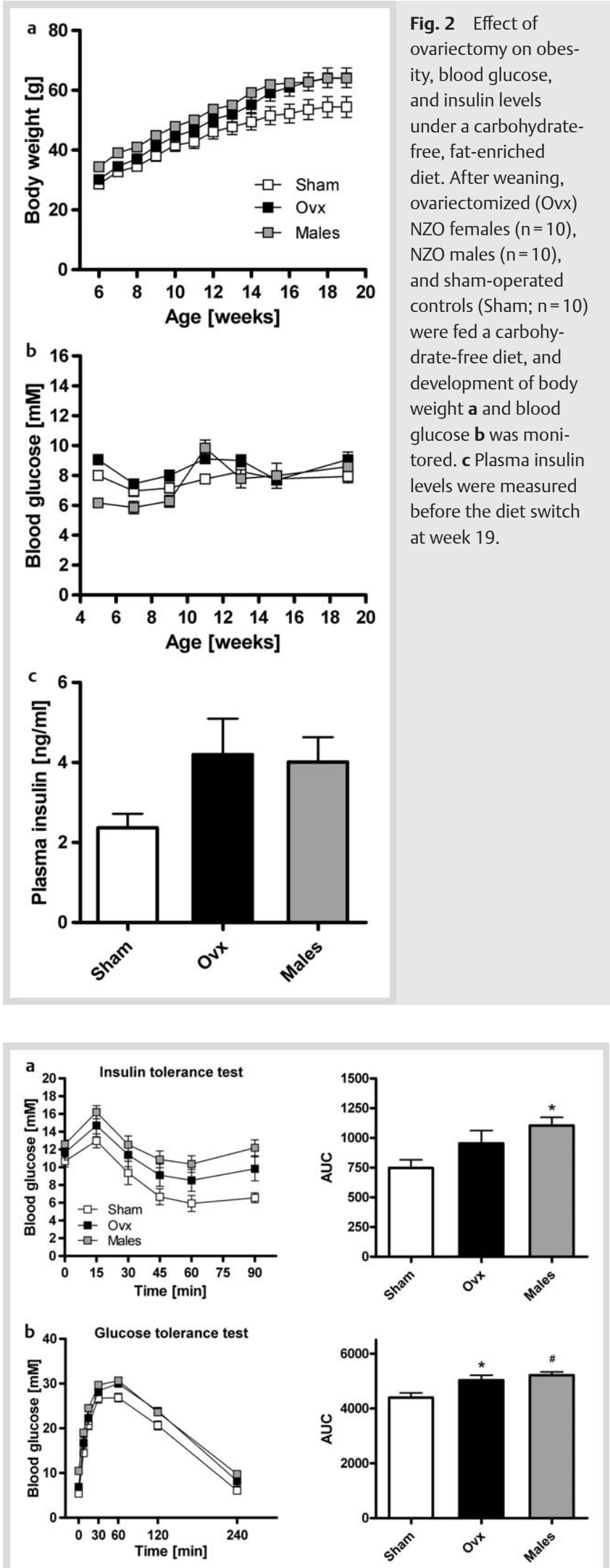

Fig. 3 Effect of ovariectomy on insulin resistance under a carbohydratefree, fat-enriched diet. Glucose homeostasis was analyzed by performing an insulin (a, ITT) and glucose tolerance test (b, oGTT). Blood glucose levels (left panels) and AUC (right panels) in $6 \mathrm{~h}$ fasted animals were calculated during ITT and in overnight-fasted mice during oGTT. Data represents means \pm SEM of at least 10 mice. $p$-Values represent differences to the sham group $\left({ }^{*} \mathrm{p}<0.01 ; \# \mathrm{p}<0.05\right)$.

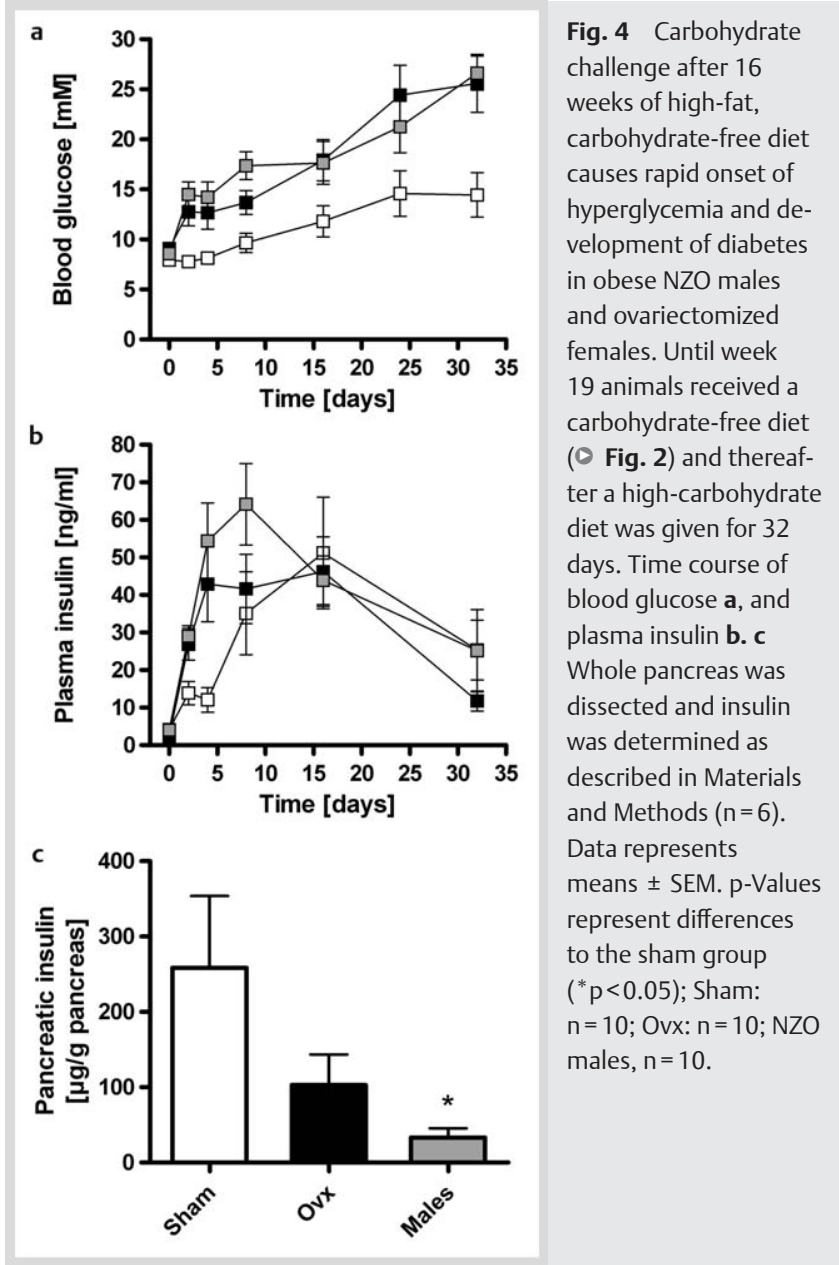

suggest that ovariectomy aggravated the obesity-associated insulin resistance.

\section{Ovariectomy causes insulin depletion in NZO females after re-exposure to carbohydrates}

After 16 weeks on the carbohydrate-free diet ( $\odot$ Fig. 2), mice were exposed to a diet containing carbohydrates, and blood glucose as well as plasma insulin levels were monitored over a period of 32 days ( $\odot$ Fig. 4). This re-exposure caused a rapid increase in blood glucose levels in estrogen-deficient females as well as in NZO males, both groups passing the diabetic threshold ( $16.6 \mathrm{mM}$ ) between day 15 and 25 . In contrast, blood glucose levels in the sham group remained below $16.6 \mathrm{mM}$ and were significantly lower than those in the ovariectomized group and in NZO males at all time points ( $\bullet$ Fig. 4a). Plasma insulin levels increased in all 3 groups after carbohydrate exposure until days 10-15 and declined thereafter. At day 3 and 5, insulin levels were markedly lower in the sham-operated females than in ovarectomized or male NZO ( $\bullet$ Fig. 4b). This finding is consistent with the conclusion that male and ovariectomized NZO females present a more severe insulin resistance than female controls. It remains unclear, however, why the female controls exhibit a transient increase in plasma insulin between days 5 and 20 in spite of almost normal blood sugar levels.

After 32 days of exposure to dietary carbohydrates, the insulin content of total pancreas was considerably higher in sham-operated female controls than in ovariectomized females and males ( $\bullet$ Fig. 4c). This result is consistent with the conclusion that dia- 
betes in male and ovariectomized females is ultimately due to insulin depletion of the $\beta$-cells, presumably caused by the deleterious effects of chronic hyperglycemia.

\section{Discussion}

$\nabla$

The present data indicate that ovariectomy of NZO females reverses their diabetes resistance and produces a phenotype which is comparable with that of NZO males. From these data, we conclude that estrogen protects against the development of diabetes. This protection is due to enhanced insulin sensitivity without a major alteration in weight development or fat accumulation. In addition, it cannot be excluded that estrogen protects from the glucolipotoxic conditions causing $\beta$-cell loss. Consequently, NZO mice are a suitable model to elucidate the molecular basis of this protective effect.

Our data are consistent with previous studies demonstrating that lack of estrogens reduces insulin sensitivity and causes impaired glucose tolerance $[7,8]$, and extends them in showing that lack of estrogens can produce $\beta$-cell loss in an obese mouse model. This conclusion is consistent with previous data indicating that the high prevalence of diabetes in female $\mathrm{db} / \mathrm{db}$ mice is due to a high activity of hepatic steroid sulfotransferases which inactivates estrogens [15].

Obesity is a critical factor in the pathogenesis of insulin resistance and type 2 diabetes. In our NZO model, ovariectomy had minor, if any, effects on the development of obesity. However, different studies in rodents and in humans indicated that estrogens play a pivotal role in white adipose tissue (WAT) physiology and in the development of obesity. After surgical removal of ovaries, a protective effect of estrogens with respect to obesity is eliminated and can be reversed by the application of estrogen [16-18]. Reduced levels of circulating estrogen as present in transgenic mouse models result in a significant increase in abdominal adiposity $[8,19]$. It has been shown that estrogen comprises the ability to decrease food intake by a proposed direct or indirect interaction with orexigenic and anorexigenic peptides and to promote energy expenditure, thus creating a negative energy balance and preventing obesity [20,21]. In addition, estrogen treatment has been associated with significantly reduced adipose mass and adipocyte size, possibly via decreased expression of lipogenic genes in adipose tissue, liver, and skeletal muscle (reviewed in [22]).

As previously reported by our group [12], the dietary regimen of carbohydrate restriction and the subsequent switch to a carbohydrate-containing diet dissociates the effects of obesity (lipotoxicity) from those of hyperglycemia (glucotoxicity) in NZO males. During the carbohydrate restriction, mice develop severe obesity, and are exposed to lipotoxic conditions without $\beta$-cell failure. The subsequent carbohydrate challenge provides glucotoxic conditions and leads to a rapid $\beta$-cell failure and subsequent degradation [12]. Because $\beta$-cell failure and degradation occur in a synchronized manner within a short period of 2-30 days, this dietary regimen allows studying its pathogenesis in an in vivo model. The present data indicate that NZO females have lower insulin levels than males and ovariectomized females during the period of carbohydrate restriction, indicating that estrogen has beneficial effects on insulin sensitivity. Consistent with this conclusion, females were also able to compensate the subsequent challenge by carbohydrates with initially lower insulin levels than those observed in males and ovarectomized females.
So far, we can only speculate about the cellular and molecular mechanisms leading to the protective role of endogenous estrogen in NZO females. Data from ER $\alpha$ deficient mice indicate that the beneficial effects of estrogen on insulin sensitivity and glucose tolerance in HFD-fed mice are mediated through ER $\alpha$ activation. E2 treatment reduced HFD-induced insulin resistance and improved insulin signaling (Akt phosphorylation) in insulin-stimulated skeletal muscle [16]. Unexpectedly, Riant et al. [16] also observed an enhanced expression of inflammatory factors induced by HFD in tissues directly involved in insulin action and glucose metabolism, leading to elevated plasma cytokine levels [16].

It has to be noted that few sham-operated females also developed the diabetic phenotype under the dietary regimen of carbohydrate restriction and subsequent exposure. Thus, the protective effect of estrogens appears to be antagonized by the dietary fat. Indeed, we never observed diabetes in a NZO female on a chow diet containing $15 \%$ fat, and very few cases of diabetes (2-5\%) on a diet containing $40 \%$ fat (unpublished data). Here, the dietary fat content of 51 and $71 \%$ caused a diabetes prevalence of approximately $25 \%$. Thus, the capacity of estrogen to protect from hyperglycemia appears exhausted under high-fat feeding conditions. It can be speculated that HFD treatment reduces estrogen levels or impairs estrogen signaling. Indeed, it has previously been reported that estrogen levels in NZO mice decline with age $(5.1 \pm 1.4 \mathrm{pg} / \mathrm{ml}$ at the age of 12 weeks vs. $3.2 \pm 1.0 \mathrm{pg} / \mathrm{ml}$ at 24 weeks) [23]. It is conceivable that high-fat feeding produces an age-accelerating effect in NZO females. Since the liver plays an essential role in maintaining glucose homeostasis including insulin-mediated processes such as hepatic glucose output and uptake, as well as in clearance of insulin itself [24] it can also be speculated that a fat-enriched diet results in a stronger fat accumulation in the liver and/or in the release of hepatokines, for example, fetuin A [25], or selenoprotein $P[26,27]$ that finally might increase the diabetes prevalence of NZO females.

Rodent models are important resources for investigating the physiological mechanisms underlying endocrine and metabolic disorders, and for preclinical translational studies. However, it has to be considered that the regulation of tissue androgen/ estrogen balance varies between rodents and humans and that sex differences observed in mouse models of diabetes are not consistently reflected in humans.

In summary, our data demonstrate that estrogen protects against the glucolipotoxic conditions leading to diabetes in NZO mice. This protective effect is due to a reduced insulin resistance, and possibly also to a protective effect on the $\beta$-cell. Further investigation of this protective effect in the NZO mouse model may provide important insight into the pathogenesis of type 2 diabetes.

\section{Acknowledgements}

$\nabla$

The authors are indebted to Elisabeth Meyer for expert technical assistance. This work was supported by the Deutsche Forschungsgemeinschaft (GK1208) and the German Ministry of Education and Research (NEUROTARGET: 01GI0847; DZD: 01GI0922). 


\section{Conflict of Interest}

\section{$\nabla$}

The authors declare that there is no duality of interest associated with this manuscript.

\section{References}

1 Herberg L, Coleman DL. Laboratory animals exhibiting obesity and diabetes syndromes. Metabolism 1977; 26: 59-98

2 Herberg L, Leiter EH. Obesity/diabetes in mice with mutations in the leptin or leptin receptor genes. In: Sima AAF, Shafrir E (eds.). Frontiers in animal diabetes research, vol. 2: animal models of diabetes. Harwood Academic Publishers, Amsterdam: 2001; 63-107

3 Ortlepp JR, Kluge R, Giesen K, Plum L, Radke P, Hanrath P, Joost HG. A metabolic syndrome of hypertension, hyperinsulinemia, and hypercholesterolemia in the New Zealand obese (NZO) mouse. Eur J Clin Invest 2000; 30: 195-202

4 Kluge R, Scherneck S, Schürmann A, Joost HG. Pathophysiology and genetics of obesity and diabetes in the New Zealand obese mouse: a model of the human metabolic syndrome. Methods Mol Biol 2012; 933: 59-73

5 Clark JB, Palmer CJ, Shaw WN. The diabetic Zucker fatty rat. Proc Soc Exp Biol Med 1983; 173: 68-75

6 Paik SG, Michelis MA, Kim YT, Shin S. Induction of insulin-dependent diabetes by streptozotocin. Inhibition by estrogens and potentiation by androgens. Diabetes 1982; 31: 724-729

7 Manrique C, Lastra G, Habibi J, Mugerfeld I, Garro M, Sowers JR. Loss of Estrogen Receptor $\alpha$ Signaling Leads to Insulin Resistance and Obesity in Young and Adult Female Mice. Cardiorenal Med 2012; 2: 200-210

8 Heine PA, Taylor JA, Iwamoto GA, Lubahn DB, Cooke PS. Increased adipose tissue in male and female estrogen receptor-alpha knockout mice. Proc Natl Acad Sci USA 2000; 97: 12729-12734

9 Moran A, Jacobs DR Jr, Steinberger J, Steffen LM, Pankow JS, Hong CP, Sinaiko AR. Changes in insulin resistance and cardiovascular risk during adolescence: establishment of differential risk in males and females. Circulation 2008; 117: 2361-2368

10 Saglam K, Polat Z, Yilmaz MI, Gulec M, Akinci SB. Effects of postmenopausal hormone replacement therapy on insulin resistance. Endocrine 2002; 18: 211-214

11 Louet JF, LeMay C, Mauvais-Jarvis F. Antidiabetic actions of estrogen: insight from human and genetic mouse models. Curr Atheroscler Rep 2004; 6: 180-185

12 Kluth O, Mirhashemi F, Scherneck S, Kaiser D, Kluge R, Neschen S, Joost $H G$, Schürmann A. Dissociation of lipotoxicity and glucotoxicity in a mouse model of obesity associated diabetes: role of forkhead box 01 (FOXO1) in glucose-induced beta cell failure. Diabetologia 2011; 54: 605-616

13 Jürgens HS, Neschen S, Ortmann S, Scherneck S, Schmolz K, Schüler G, Schmidt S, Blüher M, Klaus S, Perez-Tilve D, Tschöp MH, Schürmann A, Joost HG. Development of diabetes in obese, insulin-resistant mice: essential role of dietary carbohydrate in beta cell destruction. Diabetologia 2007; 50: 1481-1489
14 Klaus S. Increasing the protein:carbohydrate ratio in a high-fat diet delays the development of adiposity and improves glucose homeostasis in mice. J Nutr 2005; 135: 1854-1858

15 Leiter EH, Chapman HD, Falany CN. Synergism of obesity genes with hepatic steroid sulfotransferases to mediate diabetes in mice. Diabetes 1991; 40: 1360-1363

16 Riant E, Waget A, Cogo H, Arnal JF, Burcelin R, Gourdy P. Estrogens protect against high-fat diet-induced insulin resistance and glucose intolerance in mice. Endocrinology 2009; 150: 2109-2117

17 Park CJ, Zhao Z, Glidewell-Kenney C, Lazic M, Chambon P, Krust A, Weiss J, Clegg DJ, Dunaif A, Jameson JL, Levine JE. Genetic rescue of nonclassical ERo signaling normalizes energy balance in obese Ero-null mutant mice. J Clin Invest 2011; 121: 604-612

18 Stubbins RE, Holcomb VB, Hong J, Núñez NP. Estrogen modulates abdominal adiposity and protects female mice from obesity and impaired glucose tolerance. Eur J Nutr 2012; 51: 861-870

19 Jones ME, Thorburn AW, Britt KL, Hewitt KN, Wreford NG, Proietto J, Oz OK, Leury BJ, Robertson KM, Yao S, Simpson ER. Aromatase-deficient (ArKO) mice have a phenotype of increased adiposity. Proc Natl Acad Sci USA 2000; 97: 12735-12740

20 Brown LM, Clegg DJ. Central effects of estradiol in the regulation of food intake, body weight, and adiposity. J Steroid Biochem Mol Biol 2010; 122: 65-73

21 Eckel LA. The ovarian hormone estradiol plays a crucial role in the control of food intake in females. Physiol Behav 2011; 104: 517-524

22 Geer EB, Shen $W$. Gender differences in insulin resistance, body composition, and energy balance. Gend Med 2009; 6 (Suppl 1): 60-75

23 Radavelli-Bagatini S, Blair AR, Proietto J, Spritzer PM, Andrikopoulos S. The New Zealand obese mouse model of obesity insulin resistance and poor breeding performance: evaluation of ovarian structure and function. J Endocrinol 2011; 209: 307-315

24 Home PD, Pacini G. Hepatic dysfunction and insulin insensitivity in type 2 diabetes mellitus: a critical target for insulin-sensitizing agents. Diabetes Obes Metab 2008; 10: 699-718

25 Stefan N, Fritsche A, Weikert C, Boeing H, Joost HG, Häring HU, Schulze MB. Plasma fetuin-A levels and the risk of type 2 diabetes. Diabetes 2008; 57: 2762-2767

26 Misu H, Takamura T, Takayama H, Hayashi H, Matsuzawa-Nagata N, Kurita S, Ishikura K, Ando H, Takeshita Y, Ota T, Sakurai M, Yamashita T, Mizukoshi E, Yamashita T, Honda M, Miyamoto K, Kubota T, Kubota N, Kadowaki T, Kim HJ, Lee IK, Minokoshi Y, Saito Y, Takahashi K, Yamada $Y$, Takakura N, Kaneko S. A liver-derived secretory protein, selenoprotein P, causes insulin resistance. Cell Metab 2010; 12: 483-495

27 Yang SJ, Hwang SY, Choi HY, Yoo HJ, Seo JA, Kim SG, Kim NH, Baik SH, Choi DS, Choi KM. Serum selenoprotein P levels in patients with type 2 diabetes and prediabetes: implications for insulin resistance, inflammation, and atherosclerosis. J Clin Endocrinol Metab 2011; 96: E1325-E1329 